\title{
Spontaneous Pneumomediastinum: A Possible Severe Condition in SARS-CoV-2 Pneumonia
}

\author{
Geoffrey Jacqmin ${ }^{1}$ (1) Manuel Pirotte ${ }^{1}$ Carlo Caravaggio ${ }^{1}$ Philippe Devaux $^{1}$ \\ ${ }^{1}$ Department of Thoracic and Vascular Surgery, Centre Hospitalier \\ Wallonie Picarde, Tournai, Belgium

\begin{abstract}
Address for correspondence Geoffrey Jacqmin, MD, Department of Thoracic and Vascular Surgery, Centre Hospitalier Wallonie Picarde, Tournai, Belgium (e-mail: geoffrey.jacqmin@hotmail.com).
\end{abstract}

Thorac Cardiovasc Surg Rep 2021;10:e55-e58.

\begin{abstract}
Keywords

- spontaneous pneumomediastinum

- SARS-CoV-2

- COVID-19

Background Spontaneous pneumomediastinum (SP) is the presence of free air into extra-alveolar tissues within the mediastinum, without notion of trauma. This rare condition may occur as a complication of an underlying severe acute respiratory syndrome coronavirus 2 (SARS-CoV-2) pneumonia. Higher rates of mechanical ventilation are reported in coronavirus disease 2019 (COVID-19) patients with pneumomediastinum.

Case Description We report two cases of COVID-19 infected patients suffering from mild and severe SP and their outcome.

Discussion The objective of this report is to review the literature about this condition. We discuss about the pathological pathways underlying this complication and how it reflects the severity of COVID-19 pneumonia.

Conclusion Currently, it remains unclear if SP in SARS-CoV-2 pneumonia is a potential predictor of disease worsening, for it does not seem to be related with a higher rate of mortality.
\end{abstract}

\section{Introduction}

Since December 2019, virulent cases of severe acute respiratory syndrome from a new type of coronavirus have spread from Wuhan, China. In just 1 year, there have been 88.5 million confirmed cases of severe acute respiratory syndrome coronavirus 2 (SARS-CoV-2) infections and more than 1.9 million fatalities. ${ }^{1}$

The pandemic COVID-19 and its manifestations confronted physicians to new observations. The most common radiological signs of SARS-CoV-2 pneumonia are multifocal or subpleural ground-glass opacities with inter- or intralobular septal thickening, often involving the posterior and inferior regions of both lungs. ${ }^{2,3}$

Some cases of spontaneous pneumomediastinum in SARS-CoV-2 patients with pneumonia have been reported in the literature. ${ }^{2,4-8}$ The exact pathophysiologic mechanisms of this issue remain yet unclear. We report two cases of mild and severe onset of spontaneous pneumomediastinum in COVID-19-infected patients, while they were managed in the intensive care unit (ICU). The aim of this paper is to discuss, while reviewing the literature, about the pathological pathways underlying this complication and the possible outcomes accounting for a pejorative/non pejorative predictor issue.

\section{Case Reports}

\section{Case Report 1}

We report the case of a 49-year-old man referred to the emergency room after complaining for 1 week of dry cough, tachycardia, and dyspnea. His medical history revealed received

April 6, 2021

accepted after revision

June 24, 2021
DOI https://doi.org/

10.1055/s-0041-1735478. ISSN 2194-7635.

\footnotetext{
(C) 2021. The Author(s).

This is an open access article published by Thieme under the terms of the Creative Commons Attribution-NonDerivative-NonCommercial-License, permitting copying and reproduction so long as the original work is given appropriate credit. Contents may not be used for commercial purposes, or adapted, remixed, transformed or built upon. (https://creativecommons.org/ licenses/by-nc-nd/4.0/) Georg Thieme Verlag KG, Rüdigerstraße 14, 70469 Stuttgart, Germany
} 
arterial hypertension and kidney transplantation for polycystic kidney disease. He denied tobacco and alcohol uses. Upon admission, his oxygen saturation on room air was 93\%, his temperature was $37.2^{\circ} \mathrm{C}$, his blood pressure was $140 / 97 \mathrm{mmHg}$, and his pulse rate $92 \mathrm{bpm}$.

After performing a basic blood test, it revealed a mild Creactive protein elevation ( $11.8 \mathrm{mg} / \mathrm{L}$, reference: $<5 \mathrm{mg} / \mathrm{L}$ ). The blood count also showed a normal range of leukocytes of $4.12 \times 10^{3} / \mu \mathrm{L}$ (reference: $3.7-9.5 \times 10^{3} / \mu \mathrm{L}$ ) with lymphopenia at $1.610^{3} / \mu \mathrm{L}$ (reference: $12-47 \times 10^{3} / \mu \mathrm{L}$ ) and increased serum lactate dehydrogenase (LDH) at $261 \mathrm{U} / \mathrm{L}$ (reference: 87-241 $\mathrm{U} / \mathrm{L})$. SARS-CoV-2 infection was confirmed by a real-time quantitative reverse transcription polymerase chain reaction (RT-PCR) assay from a nasopharyngeal swab.

Chest computed tomography (CT) without contrast showed moderate diffuse alveolar damage extent (20\%) in terms of affected volume of pulmonary parenchyma. Neither pneumothorax nor pneumomediastinum was noticed at that time.

Once admitted to an internal medicine ward, the patient was given 10 days of oral corticosteroids and a preventive dose of low molecular weight heparin subcutaneously. He was also given oxygen (60 L per minute with fraction of inspired oxygen $\left[\mathrm{FiO}_{2}\right]$ on $80 \%$ ) through a high flow nasal cannula (Optiflow) on the fifth day. The next day, he was admitted to the ICU for respiratory failure requiring mechanical ventilation. On the same day, spontaneous and severe pneumomediastinum with extensive cervical subcutaneous emphysema and cardiac shift was observed on chest CT (-Fig. 1). Otherwise, an increased extent of pulmonary damage (75\% involvement of total lung volume) was assessed. The patient then faced a hemodynamic destabilization with an increased need for inotropic agents. A tracheal or bronchial rupture was ruled out by a bronchial fibroscopy. No other secondary causes of pneumomediastinum were found.

After a multidisciplinary discussion, even though we were not facing a classic pneumothorax situation, we decide in front of the critical status of the patient to perform a right lateral reduced mediastinotomy (incision in the parasternal $2^{\text {nd }}$ right intercostal space), to break down the dissected soft and fat tissue of the anterior mediastinum and to achieve thoracic drainage. This procedure performed on the $12^{\text {th }}$ day after ICU admission was effective in terms of clinical and iconographic improvement (-Fig. 2); the patient
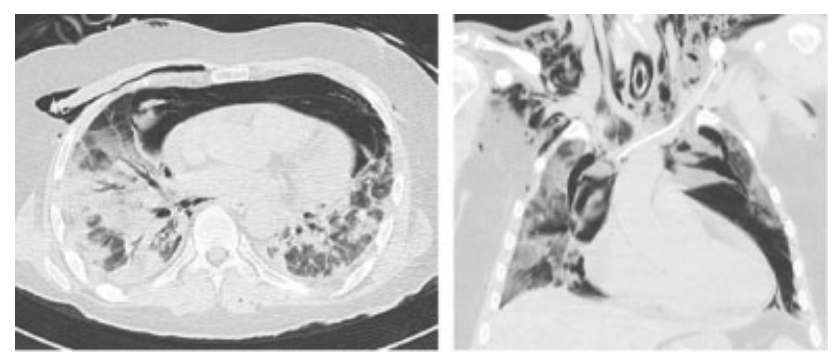

Fig. 1 Axial and coronal chest CT images showing the extent of pneumomediastinum and the cardiac shift "in progress," SP and following the main bronchi toward cardiac apex. SP, Spontaneous pneumomediastinum.
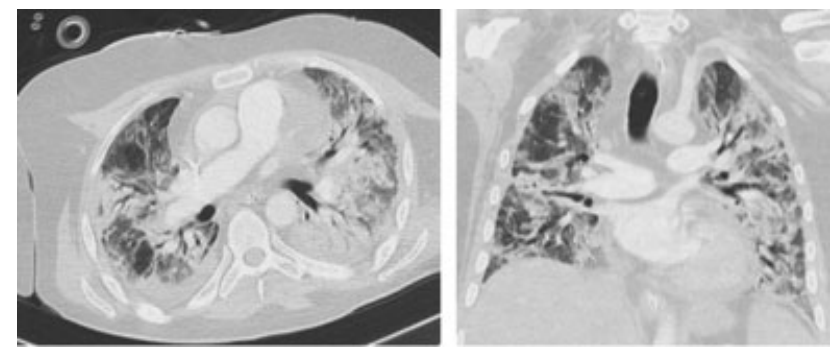

Fig. 2 Axial and coronal chest CT images after mediastinotomy. Pneumomediastinum almost resolved.

was able to be withdrawn gradually from supportive drugs and chest tube in 24 hours.

Unfortunately, the patient condition worsened again in a few days and died from respiratory failure on the $21^{\text {st }}$ day.

\section{Case Report 2}

We also report the case of a 76-year-old man who was referred to the emergency room after complaining of dyspnea for 4 days, referred by his general physician for evolving desaturation. He did not complain of cough. Only arterial hypertension was significant in his medical history. Once admitted, his temperature was $37.8^{\circ} \mathrm{C}$ and his pulse rate $173 \mathrm{bpm}$. Blood test showed an elevated C-reactive protein at $174 \mathrm{mg} / \mathrm{L}$ and a lymphopenia. RT-PCR was positive and chest CT scanner showed severe extent of alveolar damage (50\%) in terms of affected volume of pulmonary parenchyma.

Upon admission, he was admitted to the ICU for 11 days. He was later transferred to a middle care unit with a nasal high flow Optiflow set to $60 \mathrm{~L}$ of oxygen per minute with $\mathrm{FiO}_{2}$ of $60 \%$.

On the $17^{\text {th }}$ day he was readmitted in the ICU for respiratory function deterioration. The clinical course worsened, chest CTscanner was performed and showed spontaneous pneumomediastinum (SP) (-Fig. 3). He was subsequently intubated and mechanically ventilated for 5 days.

In this case, his condition was managed conservatively, and SP was progressively resolutive in a few days. The patient's general condition improved as pneumomediastinum decreased in significance. He stayed in the ICU for 29 days.

After 2 months of hospitalization, and respiratory rehabilitation, he was discharged home (-Fig. 4).
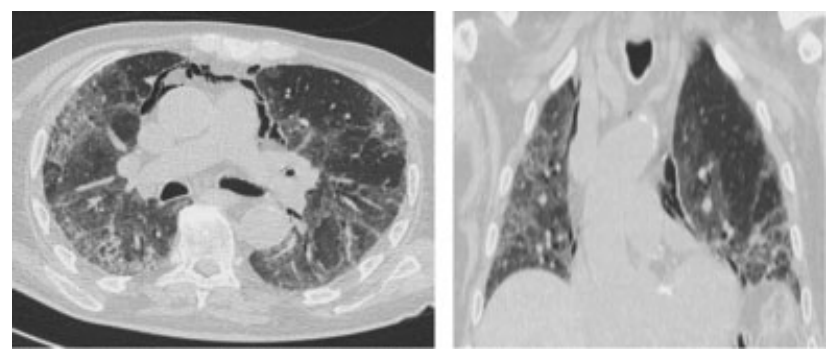

Fig. 3 Axial and coronal chest CT of the second patient with SARSCoV-2 pneumonia complicated by spontaneous pneumomediastinum. SARS-CoV-2, severe acute respiratory syndrome coronavirus 2 . 


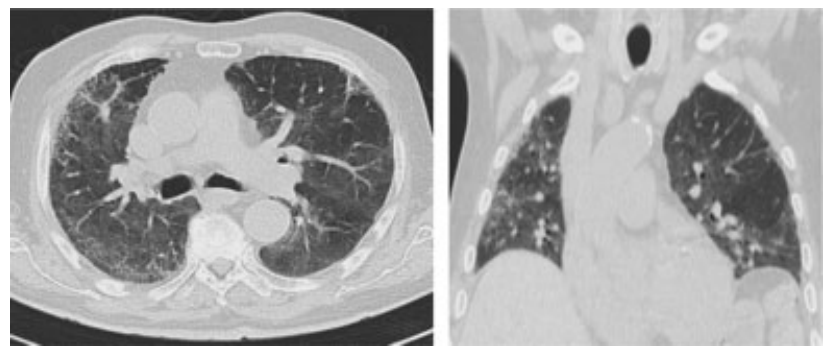

Fig. 4 Follow-up axial and coronal chest CT at 2 months after initial presentation showing complete resolution of pneumomediastinum.

\section{Discussion}

SP is the release of air into extra-alveolar tissues, most often due to alveolar rupture: free air leaks from ruptured alveoli dissects along the bronchovascular sheaths to the hilum and toward the mediastinum. This pathophysiologic process was first described by Macklin in 1939 and is called the "Macklin effect." 2,4 The Macklin effect appears on thoracic CT as linear collections of air contiguous to the bronchovascular sheaths. ${ }^{9}$

Chronic obstructive pulmonary disease, asthma, or pulmonary barotrauma during the invasive mechanical ventilation are the main risk factors. However, SP can be also a rare complication of infectious pneumonia.

- In immunocompetent hosts, SP is uncommon, it can be seen as a complication of staphylococcal or fungal pneumonia. It has also been reported to complicate interstitial pneumonitis secondary to systemic lupus erythematous. ${ }^{3}$

- In immunocompromised patients, SP is observed in Pneumocystis carinii pneumonia, tuberculosis, or cytomegalovirus pneumonitis.

Since the COVID-19 pandemic, a few SP associated with SARS-CoV-2 has been reported. Although its mechanism still remains unknown, the presumed cause is the combination of an increase intra-alveolar pressure with barotraumas due to coughing/Valsalva maneuvers or ventilation-related and diffuse alveolar injuries due to SARS-CoV-2. Prior to being hospitalized in the ICU, our patients had intense repetitive episodes of dry cough, but the iconographic proof of SP was found after the patient was intubated and mechanically ventilated.

SP is typically observed at the $20^{\text {th }}$ day $(19.6 \pm 4.6)$ from respiratory symptoms onset. ${ }^{3}$

Significantly high LDH serum level is consistently observed in SP. ${ }^{3}$ Viral load or cumulative dose of corticosteroids is typically not associated with $\mathrm{SP}^{3}$ Alveolar damages leading to SP seem not to be associated with the viral load and cytolysis. ${ }^{2,3}$ It may occur as a result of severe diffuse alveolar damage and may be related to interstitial emphysema. ${ }^{2}$ Considering the onset of this condition begins about the $20^{\text {th }}$ day in COVID-19 pneumonia, other processes than viralinduced cytolysis may relate to the pathological pathway. The important immune response in the host could be one of the reasons of SP onset.

Commonly, SP responds favorably to conservative treatment and resolve with a reduction in ventilatory pressures
Table 1 Surgical indications to perform a pleural with or without mediastinal open drainage

\begin{tabular}{|l|}
\hline Tension pneumothorax \\
\hline Mediastinal shift \\
\hline Cardiac tamponade \\
\hline Hemodynamic instability \\
\hline Significant subcutaneous emphysema \\
\hline
\end{tabular}

and close monitoring. ${ }^{10}$ Rarely, patients develop tension pneumomediastinum, in whom a mediastinotomy with chest drainage should be performed. ${ }^{10}$ Uni or bilateral pleural drainage possibly combined with a reduced mediastinal approach (through a simple and reduced parasternal incision at the level of the $2^{\text {nd }}$ intercostal space) is presumably the good option when patient presents a mediastinum shift associated with hemodynamic instability related to the free air release which increases intrathoracic pressure, as in our case report 1. Indeed, severe SP first decreases venous return, preload is then affected reducing cardiac output and leading to an imminent death if not treated. In this severe condition and based on CT and clinic evaluation, we think that performing a fast pleural/mediastinal drainage is mandatory. This drainage procedure will restore in a few hours an optimal intrathoracic pressure with normalization of the cardiac shift and hemodynamic parameters. Tension pneumothorax with pulmonary collapse is also an obvious indication for an immediate chest tube placement procedure. Significant cervicofacial subcutaneous emphysema should imply in the same way a thoracic drainage (-Table $\mathbf{1}$ ).

We summarize from the literature 13 patients who suffered from SP in SARS-CoV-2 pneumonia (-Table 2). Reports or descriptions of mild/severe SP in COVID-19 pneumonia are quite rare, as the occurrence of this pathology is also infrequent, even during SARS-CoV-2 pandemic and with patients being often mechanically ventilated. In our review, except one patient, all SP cases have been managed conservatively. No data has been recorded so far on thoracic/mediastinal open management of SP in SARSCoV-2 pneumonia. This might be explained by the SP described as "severe" by many authors with CT scans revealing in fact mild to small pneumomediastinums and thus not at risk of promoting a dreadful cardio-mediastinal shift as in our first case report. It is fortunate that a severe case of SP as we encountered seems indeed to be extremely rare.

Some reports affirm SP in COVID-19 patients is a risk factor of intubation and mortality. ${ }^{2,4-8}$-Table 2 leads to confirm the higher rate of intubation, but higher rate of mortality is certainly overestimated.

It was shown that "moderate or mild" SP required a median of 28 days to resolve entirely. ${ }^{3}$ Presumably, pneumomediastinum in COVID-19 pneumonia is observed in long and severe course of disease.

In conclusion, spontaneous pneumomediastinum is a rare complication in SARS-CoV-2 pneumonia and seems to be 
Table 2 Patients who suffered from SARS-CoV-2 pneumonia and SP retrieved in six reports ${ }^{2,4-8}$

\begin{tabular}{|c|c|c|c|c|c|}
\hline Authors & Study population & $\begin{array}{l}\text { Radiological extension } \\
\text { of pneumomediastinum }\end{array}$ & $\begin{array}{l}\text { Days from onset of } \\
\text { symptoms to } \\
\text { SP detection }\end{array}$ & Management & Outcomes \\
\hline Janssen et al & 52 y, male & Small & 7 & $\begin{array}{l}\text { Conservative including } \\
\text { mechanical ventilation }\end{array}$ & Discharged \\
\hline Gorospe et al & $\begin{array}{l}\# 1: 65 \mathrm{y} \text {, female } \\
\# 2: 60 \mathrm{y} \text {, female } \\
\# 3: 62 \mathrm{y} \text {, male } \\
\# 4: 58 \mathrm{y} \text {, male }\end{array}$ & $\begin{array}{l}\text { Severe } \\
\text { Severe } \\
\text { Moderate } \\
\text { Moderate }\end{array}$ & $\begin{array}{l}20 \\
12 \\
19 \\
18\end{array}$ & $\begin{array}{l}\text { All four cases were } \\
\text { managed conservative- } \\
\text { ly including mechanical } \\
\text { ventilation }\end{array}$ & $\begin{array}{l}\text { Discharged } \\
\text { Death from infectious } \\
\text { complication } \\
\text { Discharged } \\
\text { Discharged }\end{array}$ \\
\hline Mohan and Taussen & 49 y, male & $\begin{array}{l}\text { Severe with extensive } \\
\text { subcutaneous emphysema }\end{array}$ & 8 & Conservative & Discharged \\
\hline Diaz et al & $\begin{array}{l}\# 1: 51 \mathrm{y}, \text { male } \\
\# 2: 37 \mathrm{y} \text {, male } \\
\# 3: 34 \mathrm{y} \text {, male }\end{array}$ & $\begin{array}{l}\text { Moderate } \\
\text { Severe } \\
\text { Small }\end{array}$ & $\begin{array}{l}18 \\
19 \\
50\end{array}$ & $\begin{array}{l}\text { Conservative. Only the } \\
51 \text {-year-old patient re- } \\
\text { quired mechanical } \\
\text { ventilation. }\end{array}$ & $\begin{array}{l}\text { Discharged } \\
\text { Discharged } \\
\text { Discharged }\end{array}$ \\
\hline Kolani et al & 23 y, female & Small & Unknown & Conservative & Discharged \\
\hline
\end{tabular}

Abbreviations: SARS-CoV-2, severe acute respiratory syndrome coronavirus 2; SP, spontaneous pneumomediastinum.

Source: Permission to reprint has been obtained.

associated with a higher rate of intubation/mechanical ventilation. SP in COVID-19 pneumonia does not seem to be related with a higher rate of mortality, such as described in the literature. Surgical management may be used in selected patients if conservative management is insufficient. Further research is needed to assess if this underlying complication of COVID-19 pneumonia is an indicator of disease worsening.

\section{Conflict of Interest}

None declared.

\section{References}

1 World Health Organization. Coronavirus Disease (COVID-19). Accessed October 01, 2021 at: https://covid19.who.int

2 Janssen J, Kamps MJA, Joosten TMB, Barten DG. Spontaneous pneumomediastinum in a male adult with COVID-19 pneumonia. Am J Emerg Med 2021;40:228.e3-228.e5

3 Chu CM, Leung YY, Hui JY, et al. Spontaneous pneumomediastinum in patients with severe acute respiratory syndrome. Eur Respir J 2004;23(06):802-804
4 Gorospe L, Ayala-Carbonero A, Ureña-Vacas A, et al. Spontaneous pneumomediastinum in patients with COVID-19: a case series of four patients. Arch Bronconeumol 2020;56(11):754-756

5 Mohan V, Tauseen RA. Spontaneous pneumomediastinum in COVID-19. BMJ Case Rep 2020;13(05):e236519

6 Diaz A, Patel D, Sayedy N, Anjum F. COVID-19 and spontaneous pneumomediastinum: a case series. Heart Lung 2021;50(02): 202-205

7 Volpi S, Ali JM, Suleman A, Ahmed RN. Pneumomediastinum in COVID-19 patients: a case series of a rare complication. Eur J Cardiothorac Surg 2020;58(03):646-647

8 Kolani S, Houari N, Haloua M, et al. Spontaneous pneumomediastinum occurring in the SARS-COV-2 infection. IDCases 2020;21: e00806

9 Murayama S, Gibo S. Spontaneous pneumomediastinum and Macklin effect: overview and appearance on computed tomography. World J Radiol 2014;6(11):850-854

10 Shennib HF, Barkun AN, Matouk E, Blundell PE. Surgical decompression of a tension pneumomediastinum. A ventilatory complication of status asthmaticus. Chest 1988;93(06):1301-1302 